\title{
Moderating Effect of Market Environment on the Relationship of Corporate Social Responsibility and Firm Performance of Banking Sector in Pakistan
}

\author{
Mansoor Alam Khan $\quad$ Riaz Ahmad ${ }^{\dagger} \quad$ Mubashira Fatima ${ }^{\ddagger}$
}

\begin{abstract}
In the current environment, firms' performance is reflected to be a significant aspect of their competitive edge. If the firm's performance cannot be improved, its competitive advantage might be decreased. It was noted in the literature that the performance of the Pakistani banking industry had decreased. Besides these concerns, there are numerous other factors that are related to declining performance. Among them, corporate social responsibility (CSR) is also included. Therefore, the objective of this study is to examine the moderating effect of the market environment on the relationship between corporate social responsibility and firm performance in the banking sector in Pakistan. Using cross-sectional data techniques for the collection of data from 296 managers of the banking sector within Pakistan, a Partial least squares (PLS)-structural equation modelling (SEM) technique is applied to analyse the data. Results show that CSR and all its dimensions (CSR towards customers, CSR towards employees, CSR towards society, and CSR towards government) have a positive and significant influence on FP, and the market environment does not moderate the impact of corporate social responsibility and firm performance. The findings of this research highlight the importance of CSR in the banking sector of Pakistan. Underneath the theoretical shadows of stakeholder theory, this research adds to the existing body of literature by suggesting that the significance of the market environment does not enhance the association between CSR and FP. This research would also provide valuable insights for banks to capitalise on their CSR resources to sustain organisational performance.
\end{abstract}

Keywords: Corporate social responsibility, Government, Employees, Customers, Society, Market environment, Firm performance, Banking sector, Pakistan.

\section{Introduction}

Modernization of the service sector has discovered new dynamics through commercialization and industrialization, while, on the other hand, they have rooted the use of nonrenewable sources of energy in global warming and climate change, greenhouse gas emissions, and increasing levels of waste and pollution, all of which have adverse consequences for the next generation (Dhingra \& Mittal, 2014). For this reason, in part due to the increased analysis of businesses in the effects of the global financial crisis, the evolving nature and perception of businesses' position in society is a point of concern. Since

\footnotetext{
${ }^{*}$ Assistant Manager Finance, Iftekhar Ahmed \& Co, Karachi, Pakistan. Email: m.mansooralamkhan@gmail.com

${ }^{\dagger}$ Faculty of Business Administration, Iqra University Karachi, Pakistan. Email: riaz.ahmad@iqra.edu.pk

‡Student, Iqra University Karachi, Pakistan. Email: mubashira.14426@iqra.edu.pk
} 
companies have a direct association with the society in which they function, several social rules must be enforced to strengthen this relationship. The policies concerning such activities are referred to as CSR activities (Schwartz \& Cragg, 2017). Therefore, today, in an open market environment, many businesses consider CSR to be a strategic necessity.

Furthermore, from a theoretical perspective, CSR is defined as a company's activities for social benefit irrespective of economic interests. Since stakeholders have an ability to influence corporate activities and management (Ramchander, Schwebach, \& Staking, 2012), the current study examines the CSR-FP relationship using stakeholder theory and treating CSR as a multivariable construct. As negative consequences of organizations' activities are the main concern of society, companies are more worried about the influence of stakeholder theory's ethical and liable treatment of all stakeholders on company performance. Despite the obvious financial cost of balancing the economic interests of stockholders with the ethical, collective, and environmental concerns of further stakeholders, a significant number of today's top business executives have greatly spent on CSR activities. Outcomes, such as enhanced employee productivity, consumer satisfaction, and other social capital, these executives reasoned, critically compensate for the costs of socially responsible behaviour (Parket \& Eilbirt, 1975). Alternatively, some researchers still believe that companies that put resources into CSR activities are expected to be economically deprived compared to companies that do not invest in CSR. This is due to the belief that such investments do not return in economic remuneration (Aupperle, Carroll, \& Hatfield, 1985).

Besides from the theoretical perspective, from an empirical point of view, the association of CSR and FP has been a source of discussion among researchers since 1960 (Carroll \& Shabana, 2010). Several researchers have claimed that CSR has a positive effect on FP. In contrast, some have reported negative effects from this relationship (Chen, Hung, \& Wang, 2018). However, some other researchers have argued that there are U-shaped relationships between the CSR and FP. Hence, there was an inconsistency in the findings of the existing research (Bagh, Khan, Azad, Saddique, \& Khan, 2017). Therefore, as advised by Baron and Kenny (1986), a moderator is used in this study, namely the marketing environment. Additionally, prior research has discussed the relationship between corporate social responsibility towards society, customers, and employees with firm performance, but the activity of corporate social responsibility towards government is not under discussion to the best of the author's knowledge.

Moreover, previous studies had a major focus on developed economies (Galbreath \& Shum, 2012; Loh, Thomas, \& Wang, 2017). While a little attention is paid to developing countries. Likewise, in Pakistan, there is little research on CSR and FP relationships, with the majority of them focusing on manufacturing (Anser, Zhang, \& Kanwal, 2018). However, less focus is given to the banking sector. Although this sector is the pillar of the economy of any country (Ehsan et al., 2018). In this connection, the State Bank of Pakistan reported that the trend of total profitability of the banking sector has decreased continuously. From 2016 to 2017. In 2016, total profit (Rs in millions) was 229,353,126 and in 2017 , it was $238,063,597$. Income has increased significantly. However, from 2018, the profit declined as compared to previous years. In 2018, total profit was $175,672,651$; then it collapsed in 2019 to a loss of 1,043,303; and this year, the banking sector faces losses. 
On the basis of all the above-stated grounds, a need is observed to investigate the impact of CSR on the FP of selected Pakistani banks listed on the stock exchange (PSX). Therefore, this paper is an effort to scrutinise the connection between CSR and firm performance, also taking the market environment as a moderator in Pakistan's banking sector. Furthermore, this paper considers customers, suppliers, society, and government as CSR activities.

\section{Literature Review}

The ensuing paragraphs present the available literature on the subject both from theoretical and empirical perspective:

\section{Theoretical Background}

This research, observed that CSR from the perspectives of various stakeholders, defining it as a company's voluntary consideration of stakeholder interests either in or out of its business operations. As a result, CSR, as described in this report, denotes to companies' voluntary actions that go beyond exclusively economic goals (Homburg, Stierl, \& Bornemann, 2013). Individuals or groups with the ability to influence corporate activities and for corporate management whose interests have implications are refers to as stakeholders. Stakeholder includes Employees, consumers, stockholders, vendors, and others are among the company's stakeholders, each of whom has a valid interest in the company's operations.

Primary and secondary stakeholders have been identified in stakeholder theory. Primary stakeholders are engage actively and consistently in the activities of the focal company, and their participation is critical to the firm's survival. Customers and workers are regarded as the most significant primary stakeholders because they contribute the most to a company's success. Secondary stakeholders are the community members or voluntary organisations, don't actively interact with the focal firm but have an indirect impact on it. For example, society is a secondary stakeholder because it takes indirect effects on company and the society is affected by the company's operations (McCarthy, Puffer, Dunlap, \& Jaeger, 2012).

This research focuses on CSR in relation to four stakeholder groups' employees, customers, society, and government. The two most significant primary stakeholders are employees and consumers, but we include society and government because CSR against society is the main components of the CSR philosophy. While primary stakeholders (such as customers and employees) have the greatest impact on a company's success (Homburg et al., 2013). Stakeholder reactions to a company's charitable activity, which makes society as significant as primary stakeholders do. In conclusion, these groups subsidize much more to a company's market success. As a result, CSR with its stakeholders is classified as enterprises' charitable behaviors that are beyond the pure economic concern and intention to positively affect various stakeholder groups. In particular, CSR to employees is described as companies' voluntary consideration of workers' concerns and benefits (Turker, 
2009); CSR to society is classified as companies' volunteer consideration of social concerns concentrating on a wider notion of sustainability. CSR in relation with customers applies to a company's voluntary consideration of customers' needs inside and outside the business operations. Whereas, when it comes to CSR and the government, the government's participation in strengthening CSR is critical. Public sector entities may choose to follow a laissez-faire strategy or support voluntary norms for market-driven CSR problems, such as director compensation. CSR concerns with weak market drivers and no viable business case may imply increase roles for the public sector to produce incentives, such as regulatory reform, strategic alliance negotiations with business or civil society.

\section{Firm Performance}

Successful firms are a significant element for establishing countries. Most economists contrast them to an engine in terms of determining their political, social and economic development. All organizations should perform under performance-based criteria in order to compete in current economy. Nowadays, Firm performance is a relevant construct in strategic management research around the world, and it implemented usually as a dependent variable. Despite its significance, there seems to be few agreements on its description, dimension, \& quantification, which limit research progress. The act as a concept of a firm's success or its efficiency and as an indicator of the organizational style in which it is operating effectively to ensure \& achieve its objectives successfully. Moreover a firm to be performant when it is both efficient and effective. As a result, efficiency and efficacy are two characteristics that influence performance.

\section{Corporate Social Responsibility}

Now a days competitive market environment, CSR is viewed as a strategic need by many firms. According to the CECP (Chief Executives for Corporate Purpose) Giving in Numbers 2013 survey, the Fortune 500's top 100 corporations donated \$60.95 million in 2012 (.09 percent of total revenue) (Bai \& Chang, 2015). For instance, According to smith in 2011, Wal-Mart contributed 4.5 percent of its pre-tax income to support around 50,000 charities. Corporate Social Responsibility acknowledges that businesses carry a variety of responsibilities, including economic and legal responsibilities (Dhingra \& Mittal, 2014). As per Frederick (2016), "A company has only one social responsibility: to make good use of its resources and engage in activities that maximize profits as long as it follows the rules of the game, i.e. participates in fair and open competition without deception or fraud." Dhingra and Mittal (2014) recompensing to the society, contributing in charitable projects, and contributing positive social value are all aims and objectives of CSR. Businesses are gradually turning to CSR to make a modification \& generate a meaningful brand. Frederick, evaluate the four stages of CSR development (1950s-1960s) suggested that public interest, that managers should serve happily as public trustees;(1960s-1970s) urged that every firm require a legal corporate response toward social needs;(1980s-1990s) proposed that companies constructed an ethical culture for the propose of the stakeholders and communities uses through societal agreements; and discovered the adverse influence of 
businesses on society \& environment which firm must concern for the whole society organizations necessity to set accurate.

\section{Empirical relationship and hypothesis development}

A number of studies are conducted on the relationship between CSR activities and FP (Baird, Geylani, \& Roberts, 2012) and there is no agreement between researchers on whether CSR and FP have a neutral, positive, or negative relationship. Most of the researcher concluded that the connection between CSR and FP is positive (Govindarajan \& Amilan, 2013; Ikram et al., 2019; Iqbal, Ahmad, \& Kanwal, 2013). And they recommended investment on the CSR activities in order to improve the value of organizations. On the contrary, many researcher conclude a negative link between CSR and FP and they opposed the idea of allocating resources to CSR. This disparity within the outcomes of the researchers is because of the difference in the pattern of selection and procedures connected to petition of variables of their studies (Girerd-Potin, Jimenez-Garcès, \& Louvet, 2014). CSR might be selected to particular corporate individual customers and groups (Carroll \& Shabana, 2010).

Therefore, the focus of this research is on CSR in relation to four stakeholder groups' staff, consumers, society and government. Customers and employees are the two most significant major stakeholders, but we also include society and government because social responsibility is one of the most important aspects of the CSR idea. While the government refers to as external stakeholder, which, has indirect, affects a company's CSR practices. Finally, these four activities contribute the most to a company's market success.

CSR towards employees, CSR towards Employees leads to the Organization's voluntarily concerns and desires about the workers. $F P$.

$H_{1}$ : There is a significant relationship between CSR towards Employees as a relationship with

CSR towards society, CSR is categorize as activities that go beyond a business's pure economic interests that contain activities that benefit society. This concept highlighting on CSR actions against society, emphasising the wider characteristics of sustainability (Homburg et al., 2013).

$\mathrm{H}_{2}$ : There is a significant relationship between CSR towards Society as a relationship with FP.

CSR towards customers, relates to a company's willingness to consider client needs both internal and external business operations (Turker, 2009). $F P$.

$H_{3}$ : There is a significant relationship between CSR towards Customers as a relationship with

CSR towards government, the effectiveness of legal systems in preventing unethical business practices. 
$H_{4}$ : There is a significant relationship between CSR towards Government as a relationship with FP.

Figure 1

Conceptual Framework

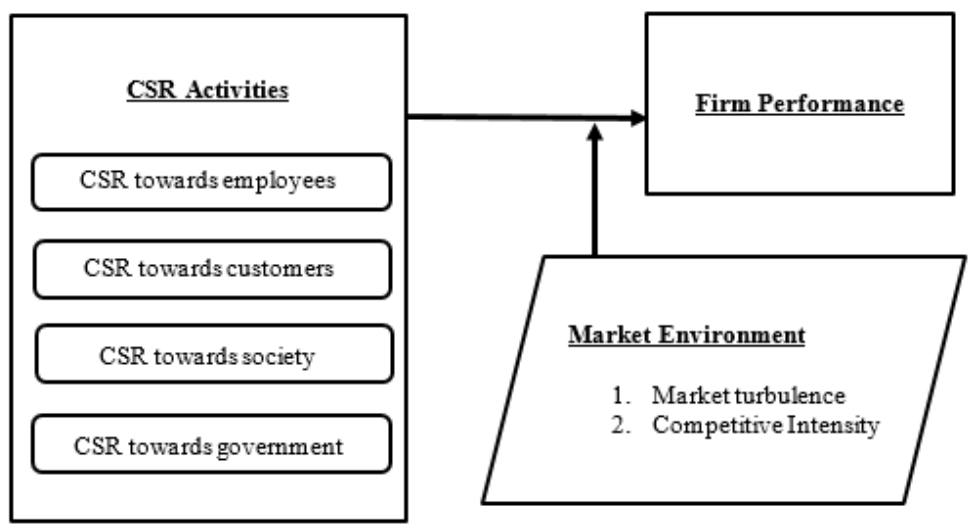

\section{Moderator}

Furthermore, another school of thought found a significant association between CSR and $\mathrm{FP}$, recorded a vague relationship, and urged that researchers take into account a slew of other factors that could impede their findings (Adeneye \& Ahmed, 2015; Mehar, Rahat, et al., 2007; Soana, 2011). Hence, the ambiguous CSR-performance correlation could alternatively be due to a "missing factor" that explains the observed relationship, thus underlying mechanisms or a contingency condition. In addition, we consult the study on strategy-environment fit (Venkatraman \& Prescott, 1990) and recommend that Market Environment including competitive intensity and market turbulence moderates the relation concerning CSR and FP. Furthermore using a moderator in case of inconsistent findings is also advised (Baron \& Kenny, 1986).

$H_{5}$ : Market environment significantly moderates the relationship between CSR towards employees and firm performance.

$H_{6}$ : Market environment significantly moderates the relationship between CSR towards society and firm performance.

$H_{7}$ : Market environment significantly moderates the relationship between CSR towards customers and firm performance.

$H_{8}$ : Market environment significantly moderates the relationship between CSR towards government and firm performance. 


\section{Research Methodology}

There are three different categories of research design. Qualitative research, Quantitative research, Mixed Method research. In qualitative research, non-numerical records are collected, analyzed, and interpreted in order to better understanding of concepts, opinions, and experiences (Berrios \& Lucca, 2006). Quantitative research is the process of gathering and analyzing numerical data to characterize predict or regulate variables of interest. The objectives of quantitative research are to test causal relationships between variables. Mixed method is a merge of quantitative and qualitative research. Quantitative research design is applied for the current study. Moreover, this study used the cross sectional research design whereby the data are collected at single time. This study method is preferred when the researcher wants to describe the relation between variables and perform hypothesis testing (Ab Talib, Rubin, \& Zhengyi, 2013). Hence, according to this study, we apply the cross sectional research design. In comparison to the qualitative research approach, the quantitative research approach and cross- sectional study design has more reliability, validity, and regarded to have a greater impact.

\section{Target Population, Sampling Techniques and Data Sources}

For this research, overall banking sector of Pakistan was targeted through a non-probability convenient sampling technique of data collection. Large sample of data is essential for this research as this study in obtaining Structural Equation Modelling (SEM) to test and analyses the model.

The selected sample for this research is 500 which is reflected as very good sampling number to judge. Managers from each bank were chosen to examine at the current study's objective through online survey questionnaire method. Self-administrated questionnaires were used to collect data because they are the most well-known method for these type of research it is used examine people response and perceptions. Furthermore, according to (Erard, Meyer, \& Viglione, 2014) surveys are time and money consuming, but they reach the bulk of the people who need to be examine, and question coding is simple, allowing for quick analysis. The questionnaire distributed to the responders with a cover letter that included an introduction to the variables and the study's goal. Organizations received personal distribution of the researcher surveys. Moreover the responders were informed about the confidentiality of their data and other ethical considerations.

\section{Measurement and Questionnaire Description}

This section enlightens that how to measure and Systematize variables such as corporate social responsibility, market environment and firm performance. For data collection strategy, there is no appropriate rule. So as a result, the researcher can only follow these general rules for the research instrument that is believe to be appropriate for achieving the research objective. According to prior research, the researcher should assure that the collected data can answer the research questions and also achieve the research objectives 
using the instrument that is being used in the research (Hair, Money, Samouel, \& Page, 2007).

This paper is based on primary data, and it used a self-administered questionnaire for data collection. The key reasoning for applying a self-administered questionnaire is that it allows respondents to react quickly while simultaneously providing the researcher to collect and analyze results more efficiently. The reliability of data and validity of the selfreport measures is endorse by a survey adapted as the most suitable data collection and prior study tool (Bai \& Chang, 2015).

There are three types of variables in the current study research instrument, in which one independent factors, one moderating variable, and one dependent variables among these variables. In terms of independent variables, We adapted Turker (2009)'s scale to measure CSR toward four major stakeholders employees, consumers, Society and government. For the moderators, we used items adopted from Bai and Chang (2015) to assess market turbulence and competitive intensity. The four items used to assess market turbulence reflect the difficulties in forecasting market trends, customer demand, sales, and industry volumes. Competitive intensity measures how often a company engages in promotional warfare, pricing battles, and competitive forgery. To evaluate FP, this research uses three items that is adopted from Bai and Chang (2015) to determine the rate of growth, returns on investment, and total profitability of a company.

The 5-point Likert Scale will used to assess all of these variables. In addition, 5point Likert scale approach allows for greater communication with respondents. As a result, the Likert scale included five measures 1-strongly disagree, 2-disagree, 3-neutral, 4- agree, 5-strongly agree. Many researches have been conducted using the 5-point Likert scale because they used perceptual measures and obtained data that was ordinal in nature (Kafetzopoulos, Gotzamani, \& Skalkos, 2019).

Before to doing any types of assessment, it is critical to pay close attention to how the questionnaire will be design. A, B, C, D, E, and F are the six sections in which the ques-

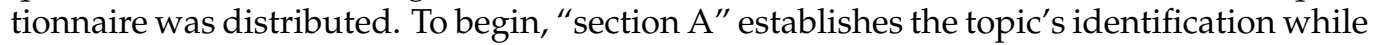
also explaining the study's primary objective. Second, part B contains the background information, which includes the name of the organization, job description, gender, age, educational background, and relevant work experience of respondent. Finally, part $C$ has all independent variable questions. Finally, section D has a moderating variable that is use to obtain data from respondents. In the section E, dependent variable will be discuss and finally, section F includes a remark for the responders' comments.

\section{Data Analysis and Data Presentation}

\section{Data Validation and Verification}

This part examines the response rate, data coding and entering, data screening and at the end cleaning prior to the statistical analysis. Further details are discussed below: 


\section{Response Rate}

The questionnaire consisted of six sections, which gave to the study participants online. The researcher provided details personally. Since many people had never heard of CSR, Market environments and FP before, the researcher briefed them on those topics. The time of data collection for research took from June to August 2021. An online survey has been taken of 500 managers employed in the banking sector of Pakistan. A total sample rate of $100 \%$ was provided to the manager population, but only 335 returned their forms, resulting in $67 \%$ response rate.

The left over 165 respondents were eliminated from this discussion because they disagree with the opinion. The object of non-response was to have 100 persons were participating in a meeting while the other 65 were outside of the area. Another 39 respondents were unable to complete the post assessment in its entirely. Just 296 agreed to fill out questionnaire forms, representing $59.2 \%$ of the total sample. Despite the fact that this response rate is comparable to what is considered acceptable for determining the study's conclusions. According to the existing research, the response rate was also rather high due to the use of self-administrated questionnaires.

After the collection of data, the next step was to prepare a data sheet for analysis by using SPSS 23. Firstly, the Estimation Maximization (EM) was used to treat and check any missing data. EM is a tool that improves the accuracy of the overall analysis, allowing for more accurate inferences to be derived from the data. The probability of parameter estimates was used to calculate missing values. As previously indicated, 39 questionnaires were incomplete which means, there were some questions in the questionnaire that were not completely filled by the respondents.

\section{Data Cleaning}

The analysis of missing values was used with the SPSS program version 23 to analyze the missing values in the dataset. Schafer (1997) suggested that missing values of $5 \%$ or fewer are not consider as troublesome for the statistical analysis. There were only a few missing values in the variables. These responses were eliminated due to greater than percentage of $5 \%$ of missing values.

It is consequently critical to recognize outliers and apply appropriate treatments in order to obtain correct regression findings. In our data, this preliminary examination reveals that the data is free of any outliers.

When each of the independent variables are significantly correlated with each other, multi-collinearity occurs. VIF equation are used for multi-collinearity prediction. The researchers suggest that it should not be higher than VIF of 5 (Henseler et al., 2014). The results showed that all constructs had a VIF value with less than 5, which is indicating that there was no risk of multi-collinearity among constructs. 


\section{Descriptive Analysis}

Table. 4 shows the demographics of the sample, which consisted of around 296 respondents and was generated using SPSS software. The study conducted sufficient representation that shows the variations of both the genders in which 173 males (58.4\%) and 123 females (41.6\%). This shows that most of employees, which were working in the Pakistan banking sector organizations, were male. Moreover, 07 respondents that shows a $2.4 \%$ were less than 20 years, 147 respondents, which shows $49.7 \%$, were between the ages of 21 to 30 years, 113 respondents that shows a 38.2\% were between the ages of 31 to 40 . In addition, remaining 29 which shows a $9.8 \%$ were belong to above 40 years age. These descriptive had shown that in the banking sector organizations most of employees, which had an age between 21 to 30 years, are working. On the other hand, there were 12 people, which are undergraduate, which shows $4.1 \%$ of total response. In addition, 153 people which were having the degree of graduation which shows a $51.7 \%$ of total responses while 126 were having a master degree which shown a $42.6 \%$ of total responses. While, there were 05 respondents that were having the degree of PHD, which shows a $1.7 \%$ response rate. These findings had shown that banking sectors organizations are having a more graduate degree holder.

Table 1

Demographics $(\mathrm{N}=296)$

\begin{tabular}{llcc}
\hline & & Frequency & Percentage \\
\hline Gender & Male & 173 & 58.4 \\
Age & Female & 123 & 41.6 \\
& Less than 20 & 7 & 2.4 \\
& $21-30$ & 147 & 49.7 \\
\multirow{5}{*}{ Education } & $31-40$ & 113 & 38.2 \\
& Above 40 & 29 & 9.8 \\
& Undergraduate & 12 & 4.1 \\
& Graduate & 153 & 51.7 \\
& Master & 126 & 42.6 \\
& PHD & 5 & 1.7 \\
& 1 to 5 years & 139 & 47 \\
& 6 to 10 years & 35 & 11.8 \\
& 11 to 15 years & 104 & 35.1 \\
& Above 15 years & 18 & 6.1 \\
\hline
\end{tabular}

Moreover, descriptive statistics are calculated by using the SPSS. Such analyses give information about the trends in every items of the model by using measures of central tendency and measure of dispersion. For central tendency, the most frequent measure is the Mean score of the responses; however, the measure of dispersion indicates the deviation from the mean trend by calculating the SD. of the respondents. As a result, the descriptive analysis are used to get an overview of the data because it provides mean, (SD), Skewness, and kurtosis for all variables under consideration. The mean values for the independent variables namely; CSR towards customers as CSRC, CSR towards employees as CSRE, CSR towards society as CSRS, CSR towards government as CSRG. In the same vein, moderating variable is Market Environment as ME that are divided in two dimensions Market turbulence as MET and Competitive intensity as MEI and dependent variable is Firm performance as FP. These findings had shown that the entire construct 
had an above moderate level effect on the FP.

\section{Common method biased}

To check Common method biased, we used unrotated exploratory factor analysis employing Principle Component Analysis technique for testing, and used SPSS to perform Harman's single factor test. The analysis presented that the first factor contributed only $39.229 \%$ of the variance in the data that is less than $50 \%$. No single factor emerged, \& the first factor is not explicate most of the variance. Besides, if VIF value is resultant from the full collinearity test is to be less than 3.3 or equal to 3.3, then the model might be reflected a free the common method biased and the VIF values are less than 3.3. Henceforth, it is concluded that common method biased was not a hazard in this study.

\section{Assessment of Measurement Model}

\section{Convergent Validity}

The degree to which a measure that co-relates highly with another measures attempting to measure the same construct is evidence of its convergent validity. Cheah, Sarstedt, Ringle, Ramayah, and Ting (2018) argued that the degree to which measurements of the suggested latent variable are correlates to determine convergent validity. The average variance extracted (AVE) of each scale was utilized to establish convergent validity. The acceptable minimum criterion for AVE is larger than 0.5 (Fornell \& Larcker, 1981).

Table 2

Reliability and validity of the model

\begin{tabular}{lccccc}
\hline Constructs & Items & Loadings & Alpha & CR & AVE \\
\hline CSRC & CSRC1 & 0.820 & 0.787 & 0.875 & 0.701 \\
& CSRC2 & 0.811 & & & \\
CSRE & CSRC3 & 0.879 & & & \\
& CSRE1 & 0.805 & 0.800 & 0.882 & 0.714 \\
& CSRE2 & 0.886 & & & \\
CSRG & CSRE4 & 0.843 & & & \\
& CSRG1 & 0.893 & 0.735 & 0.883 & 0.791 \\
& CSRG2 & 0.885 & & & \\
CSRS & CSRS1 & 0.809 & & & \\
& CSRS2 & 0.810 & 0.827 & 0.885 & 0.658 \\
& CSRS3 & 0.835 & & & \\
MEI & CSRS4 & 0.791 & & & \\
& MEI1 & 0.817 & 0.729 & 0.847 & 0.649 \\
MET & MEI2 & 0.833 & & & \\
& MEI3 & 0.766 & & & \\
& MET1 & 0.728 & 0.710 & 0.821 & 0.534 \\
& MET2 & 0.774 & & & \\
FP & MET3 & 0.655 & & & \\
& MET4 & 0.762 & & & \\
& FP1 & 0.845 & 0.821 & 0.893 & 0.736 \\
& FP2 & 0.868 & & & \\
\hline
\end{tabular}


Convergence will be attained if all of the factor loadings for all of the products are greater than 0.5. The another way to assess reliability is to examine Cronbach's coefficient alpha, alpha scores that is exceed 0.70 are considered reliable. All of the factor loadings, Alpha, CR, and AVE results are indicated above.

CSR towards customers is the first variable which Cronbach's $\alpha$ is $0.787, \mathrm{CR}$ is 0.875 , and AVE is 0.701. The second variable is CSRE which Cronbach's $\alpha$ is 0.8, CR is 0.882 , and AVE is 0.714 . The third variable is CSRG whose Cronbach's $\alpha$ is $0.735, \mathrm{CR}$ is 0.883 , and AVE is 0.791 . The fourth variable is CSRS who's Cronbach's $\alpha$ is $0.827, \mathrm{CR}$ is 0.885 , and AVE is 0.658. The fifth variable is MEI Cronbach's $\alpha$ is $0.729, \mathrm{CR}$ is 0.847, AVE is 0.649. The sixth variable is MET Cronbach's $\alpha$ is $0.71, \mathrm{CR}$ is $0.821, \mathrm{AVE}$ is 0.534 . The seventh variable is FP Cronbach's $\alpha$ is $0.821, \mathrm{CR}$ is 0.893 , AVE is 0.736.

\section{Discriminant Validity}

As per Gefen and Straub (2005), Discriminant Validity is assessed by comparing item loadings to item cross loadings. Each item should load more heavily on its respective constructs other than more constructs. Furthermore, to establish discriminant validity, (Fornell \& Larcker, 1981) indicates that the square root of AVE in each latent variable will be higher than other correlation values between the latent variables. The discriminant validity comprises three factors; Correlation Matrix, Loadings and Cross Loadings Analysis, and HTMT Ratio.

Henseler et al. (2014) proposed the Heterotrait-Monotrait (HTMT) Ratio. It is the most current addition to the literature's support for discriminant validity tests. Computing a ratio of average correlations among constructs to the geometric mean of average correlations within items of the same constructs is required for the HTMT test.

Table 2 showed that the values are higher than threshold values and the variables are strongly correlated with each other and the values from each construct are the square root of Average variance extracted (AVE). The values of cross diagonal are more than the off diagonal's values. According to Fornell and Larcker (1981), the values of diagonal lines are greater than the rows and columns values that confirms the discriminant validity.

\begin{tabular}{|c|c|c|c|c|c|c|c|}
\hline & CSRS & CSRE & CSRS & CSRG & MEI & FP & MET \\
\hline CSRS & 0.837 & & & & & & \\
\hline CSRE & 0.613 & 0.845 & & & & & \\
\hline CSRS & 0.659 & 0.648 & 0.811 & & & & \\
\hline CSRG & 0.629 & 0.566 & 0.549 & 0.889 & & & \\
\hline MEI & 0.505 & 0.357 & 0.394 & 0.561 & 0.806 & & \\
\hline FP & 0.584 & 0.549 & 0.548 & 0.650 & 0.499 & 0.858 & \\
\hline MET & 0.393 & 0.400 & 0.373 & 0.444 & 0.472 & 0.401 & 0.731 \\
\hline
\end{tabular}

The Heterotrait-Monotrait ration (HTMT) of the items of individually variables. The items of the variable are not correspondent with each other and all the items are independent in nature. As stated by Hussain and Endut (2018) the values must be less than 0.85 in order to come upon the preferred consequence. 
Table 4

Heterotrait-Monotrait Ratio (HTMT)

\begin{tabular}{|c|c|c|c|c|c|c|c|}
\hline & CSRS & CSRE & CSRS & CSRG & MEI & FP & MET \\
\hline \multicolumn{8}{|l|}{ CSRS } \\
\hline CSRE & 0.774 & & & & & & \\
\hline CSRS & 0.813 & 0.795 & & & & & \\
\hline CSRG & 0.818 & 0.741 & 0.700 & & & & \\
\hline MEI & 0.663 & 0.466 & 0.500 & 0.767 & & & \\
\hline FP & 0.718 & 0.676 & 0.66 & 0.836 & 0.646 & & \\
\hline MET & 0.509 & 0.516 & 0.47 & 0.608 & 0.649 & 0.514 & \\
\hline
\end{tabular}

\section{Assessment of Structural Model}

The explanatory strength of the model perhaps assessed by calculating the level of inconsistency, in the dependent variable that can be predict by the model. Adjusted $R^{2}$ is thought to be important for the evaluation of a structural model and also the level of significance of the path coefficient to be calculated. For the $R^{2}$, Chen et al. (2018), defined a rule of thumb that $R^{2}$ values of $0.26,0.13$, or 0.02 for the endogenous latent constructs might be termed as substantial, moderate, and weak respectively. The $R^{2}$ for dependent variable. $51.4 \%$ for firm performance shows that the $51.4 \%$ changes in firm performance occurs due to independent variables corporate social responsibility and its dimensions.

In addition, the researcher constructs can be evaluated through effect size $f^{2}$ (Cohen, 2013). Different values of $f^{2}$ show different effect sizes. Cohen (2013) clarified that the values of $f^{2}$ within the limits of $0.35,0.15$ and 0.02 are considered as large, medium, and small respectively. Table.11 shows the $f^{2}$ of CSR towards customers is 0.016, CSR towards employees is 0.017, CSR towards society is 0.015 and CSR towards government is 0.115 . All of these exogenous variables have relatively small effect sizes expect CSR towards government, which is, consider as medium. This range of effect sizes was reasonable since there were many factors that affect Firm performance (FP). This means that the estimated model fitted the data very well.

\section{Path analysis}

\section{Direct relationship}

In this research, the hypothesis will be tested by using the structural model generated with SMART PLS, and the P-value for all of the stated values is less than 0.01 , representing that it is significant. The $t$-value of 1.96 with $p<0.5$ and 1.645 with $p<0.10$ were considered as the threshold value to support or not support the hypothesis. It hypothesized that all the relationships are positively connect to each another. In Table.12, the CSR towards customers has a significant effect on FP. $(\beta$-value $=0.133$, $\mathrm{t}$ - statistics $=2.048$ $\mathrm{p}=0.041)$ this means that H1 is supported. The CSR towards employees has a significant effect on Firm performance $(\beta$-value $=0.131$, $\mathrm{t}$-statistics $=2.093, \mathrm{p}<0.037)$ this means that $\mathrm{H} 2$ is supported. The results also revealed that CSR towards society has a significant effect on firm performance $(\beta$-value $=0.125$, $\mathrm{t}$-statistics $=2.051, \mathrm{p}<0.041)$ the mean that $\mathrm{H} 3$ is 
supported. Although CSR towards government has a significant effect on the firm performance $(\beta$-value $=0.342$, $\mathrm{t}$-statistics $=5.451, \mathrm{p}<0.000)$ this means that $\mathrm{H} 4$ is supported.

Table 5

Formal financial services

\begin{tabular}{lccccc}
\hline & Original Sample & Sample Mean & Standard Deviation & T Statistics & P values \\
\hline CSRC ->FP & 0.133 & 0.142 & 0.065 & 2.048 & 0.040 \\
CSRE - > FP & 0.131 & 0.129 & 0.063 & 2.093 & 0.030 \\
CSRS ->FP & 0.125 & 0.125 & 0.061 & 2.051 & 0.040 \\
CSRG->FP & 0.342 & 0.339 & 0.063 & 5.451 & 0.000 \\
\hline
\end{tabular}

\section{Testing Moderating Effects}

This study examined the moderating effect of market environment ME by employing the PLS-SEM using the Two-Stage approach. The two-stage approach for the moderation calculation could be applied if the objective of the study is to determine whether the moderator variable exerts a significant effect on the relationship between the exogenous and endogenous variables. As the objective for the moderation is to investigate whether the market environment (ME) significantly moderates the relationship between the corporate social responsibilities (CSR) dimensions and the Firm performance (FP) of the Pakistani banking sector. The findings of the model had shown that ME significantly moderates on the relationship of four exogenous variables namely CSR towards society, CSR towards customers, CSR towards employees, CSR towards government and the endogenous variable (FP). In the meantime, Market environment (ME) was shown to have an insignificant effect on the relationship between all independent variable with the Firm performance. All of the above discussed findings are predicted in the following table below:

Table 6

Formal financial services

\begin{tabular}{lccccc}
\hline & Original Sample (O) & Sample Mean (M) & (STDEV) & T-Stats & P-Values \\
\hline ME*CSRC - > FP & -0.039 & -0.055 & 0.074 & 0.521 & 0.602 \\
ME*CSRE - > FP & -0.097 & -0.086 & 0.084 & 1.153 & 0.249 \\
ME*CSRG -> FP & 0.020 & 0.027 & 0.077 & 0.261 & 0.795 \\
ME*CSRS ->FP $^{*}$ C & 0.048 & 0.046 & 0.073 & 0.657 & 0.511 \\
\hline
\end{tabular}

\section{Determining the Strength of the Moderating Effects}

For the $R^{2}$, Cohen (2013) defined a rule of thumb that $R^{2}$ values of $0.26,0.13$, or 0.02 for the endogenous latent constructs might be termed as substantial, moderate, and weak respectively. Table.14 predicted the information about the overall $R^{2}$ (with and without the moderating effect) for the overall analysis and then calculated the effect size. In this study, the moderation term effect size is $0.524<0.26$ which is a substantial effect; this implies that ME has a no moderating impact on the relationship between the CSR dimensions and the FP of Pakistani banking sector. 


\section{Analyzing Predictive Relevance}

The blindfolding procedure was implement to attain the value of $Q^{2}$. The blindfolding procedure is considered to only practical for dependent latent variables that hold a model specification of reflective measurement. According to Fornell and Larcker (1981), a value of $Q^{2}$ greater than 0 implies that a model has predictive relevance, whereas a value less than zero implies that there is lack of predictive relevance. A value of 0.02 indicates a small predictive relevance, 0.15 indicates a medium predictive relevance, while 0.35 indicates a large predictive relevance for the endogenous variable (Hair et al., 2014). The predictive relevance of the current structural model is 0.214 that is considered as medium. The results of predictive relevance are presented in the table below.

Table 7

R-square and Q-square

\begin{tabular}{lcc}
\hline Construct & R Square & Q Square \\
\hline Firm performance & 0.524 & 0.367 \\
\hline
\end{tabular}

This significant increase in the $R^{2}$ has shown that Market environment ME could be explain as an insignificant moderator in the relationship between CSR dimensions and firm performance.

\section{Discussion and Recommendation}

The objective of this study was to examine the moderating impact of the market environment on the relationship between the CSR of FP in banking sector of Pakistan. In alignment with this objective, four dimensions of CSR activities were employed as independent variables, namely, CSR towards society, CSR towards customers, CSR towards employees, and CSR towards government. FP was a dependent variable. ME was taken as a moderator variable, which was also a multivariable construct of market turbulence and competitive intensity as suggested by Bai and Chang (2015). The hypothesis was designed to check the significant relationship between dependent and independent variables both with and without the moderation affect. To test hypotheses, primary data was collected from the banking sector's employees in Pakistan. A total of 500 questionnaires were distributed, and 335 surveys were returned. Of those, only 296 of the 350 questionnaires submitted were used for data processing, with 39 surveys being ignored. For its evaluation, PLS-SEM was used as recommended. The 0.05 significance level was preferred in this investigation, and all of the hypotheses were two-tailed as the essential level for hypothesis decision-making. The results of PLS-SEM showed that all of the dimensions of corporate social responsibility, namely: CSR towards society, CSR towards customers, CSR towards employees, and CSR towards government, have a significant relationship with firm performance. As per the results of this research, activities of corporate social responsibility positively effect on firm performance. Additionally, the results of moderating hypotheses revealed that the relationship between CSR with dimensions and FP is not moderated by the market environment.The results of this study are compatible with 
the previous studies (Bagh et al., 2017; Ikram et al., 2019; Iqbal et al., 2013) without any doubt CSR activities and FP have a significant positive impact.

In light of above discussion, the managers of banking sector are encouraged to focus on the execution of CSR activities with the aim to improve firm performance. Because, social activities improve the assurance of organizations for the internal and external environment. Furthermore, CSR activities towards customers also relates to a company's willingness to consider client needs both within and outside of business operations (Turker, 2009). Likewise, CSR towards employees also leads to the Organization's voluntarily concerns and desires about the workers. Additionally, effective legal system is essential to guard against unethical corporate behaviors which signifies the role of CSR towards government for favorable firm performance.

Competitive intensity refers to the extent of competition that companies faces inside its industry. Intensifying competitive intensity is mark by internal rivalry with fierce price wars, heavy advertising and diverse product alternatives. In such situation of an environment, companies have two alternatives for attaining competitive advantage: deliver similar products at a lower price because of pressure caused by price wars; or differentiate their products from those offered by competitors (Bai \& Chang, 2015). Although competition has intensified in Pakistan as the number of private banks drastically increases due to the transition from a centrally planned economy to a market economy. Along with this the impact of competitive intensity does not strongly effect on CSR and FP because of undeveloped economy stakeholders are not strong enough to develop resources for attain competitive advantage.

Market turbulence is unpredictably growing and falling of the stock market. It also states to the certain extent to which an environment of the business is dynamic, difficult, and rapidly varying. Comparatively underdeveloped governmental, market, and financial institutions in Pakistan often make for highly turbulent markets due to which Pakistani markets are uncertain. In stable markets, applicants can recognize and forecast customer needs and wants by studying business reports (Fang, Palmatier, \& Steenkamp, 2008). However, accurately forecast customer needs and demands or anticipate reaction to marketing strategies in a highly uncertain market is most challenging part for firm. However, the interaction between market turbulence and CSR toward different stakeholders like, customer, society, employees and government may be insignificant. On one hand, in highly turbulent markets, customers in uncertain markets perceive high degree of risk, so customers can leave the market or switch their investment to mitigate these type of risks. While CSR in term of society and employees benefit firms segregate their brand and motivate employees, they could not support firms to predict customers' contemporary and future demands, which is critical in extremely turbulent markets. On the other hand, CSR towards government does not have any moderating effect on CSR and FP. Furthermore, Pakistan has experienced complicated \& huge market structure changes during its economic transition thus the market and organizations structures in Pakistan are very unpredictable. Moreover, market becomes more competitive in Pakistan as a number of private organizations has risen significantly of the country's transition from the planned economy system to the market economy (Bagh et al., 2017). Altogether, there are no strong theoretical justifications for the moderating effects of market turbulence on 
the effect of CSR toward different stakeholders (Bai \& Chang, 2015).

\section{Research Implications}

Theoretically previous researches has mixed findings on the relationship between CSR and FP (Bagh et al., 2017) therefore as advised by Baron and Kenny (1986), the current study has used a ME as moderator to test this relationship. Furthermore, in this study CSR is a multi-variable construct which has examined four dimensions of CSR activities on relationship with FP. In this connection, prior research has discussed CSR towards society, customers, and employees with FP, but the activity of CSR towards government is not under discussion to the best of the author's knowledge. Therefore, this study adds new insights to existing literature to facilitate academic and research concerns. Practically, FP was the dependent variable of this study which is the major concern of all organization. Since the study outcomes shows an association between CSR and FP, the management of organization can be facilitated to make smart decisions regarding investment in CSR. Similarly, the importance of government's initiatives and role can also be highlighted with support of this study.

\section{Conclusion, Limitations and Future Research}

The results have shown a significant positive relationship between CSR and FP. The stake holder's theory was applied on the model of this study that explains the effect of CSR on FP. The findings of this study also supports this theory because all the variables of CSR have influenced FP. Based on the finding it is suggested that CSR effects FP and might contribute to the economic growth of a country as well. Therefore, organization should invest in CSR activities in order to enhance their FP. Similarly, government should also make regulatory changes to promote CSR activities for national economic interest. In this study, CSR was an independent variable which was a multi-variable construct of four variables namely CSR towards customers, CSR towards employees, CSR towards society and CSR towards government. FP was a dependent variable. ME was used as a moderator variable which was also a multi variable construct of Market turbulence and Competitive Intensity. The findings further revealed that ME does not significantly moderates the relationship between CSR and FP. This could be due to limitations of this study. Since, the exclusive setting of CSR in Pakistan challenges the generalizability findings to many other developing economies. The activities of corporate social responsibility are well- received by the peoples of Pakistan, as well as Pakistani stakeholders are more likely to respond to corporate social responsibility by cooperating and supporting it. Consequently, In Pakistan the positive effects of CSR may be more pronounced. Additional this study is conducted in Pakistan on only the banking sector of Pakistan. This moderation effect ME can be tested on a broader scale with addition of other sectors like SME's, oil sector, cement sector, textile sector and also data from other developing nations to seek new insights in this regard. Lastly, CSR in this study only inspect the effectiveness toward four stakeholder groups. CSR toward other stakeholders, such as suppliers, environment and community, or many more are still unclear to the best of author's knowledge. 


\section{References}

Ab Talib, M. S., Rubin, L., \& Zhengyi, V. K. (2013). Qualitative research on critical issues in halal logistics. Journal of Emerging Economies and Islamic Research, 1(2), 1-20.

Adeneye, Y. B., \& Ahmed, M. (2015). Corporate social responsibility and company performance. Journal of Business Studies Quarterly, 7(1), 151-166.

Anser, M. K., Zhang, Z., \& Kanwal, L. (2018). Moderating effect of innovation on corporate social responsibility and firm performance in realm of sustainable development. Corporate Social Responsibility and Environmental Management, 25(5), 799-806.

Aupperle, K. E., Carroll, A. B., \& Hatfield, J. D. (1985). An empirical examination of the relationship between corporate social responsibility and profitability. Academy of Management Journal, 28(2), 446-463.

Bagh, T., Khan, M. A., Azad, T., Saddique, S., \& Khan, M. A. (2017). The corporate social responsibility and firms' financial performance: evidence from financial sector of Pakistan. International Journal of Economics and Financial Issues, 7(2), 301-308.

Bai, X., \& Chang, J. (2015). Corporate social responsibility and firm performance: The mediating role of marketing competence and the moderating role of market environment. Asia Pacific Journal of Management, 32(2), 505-530.

Baird, P. L., Geylani, P. C., \& Roberts, J. A. (2012). Corporate social and financial performance re-examined: Industry effects in a linear mixed model analysis. Journal of Business Ethics, 109(3), 367-388.

Baron, R. M., \& Kenny, D. A. (1986). The moderator-mediator variable distinction in social psychological research: Conceptual, strategic, and statistical considerations. Journal of Personality and Social Psychology, 51(6), 1173.

Berrios, R., \& Lucca, N. (2006). Qualitative methodology in counseling research: Recent contributions and challenges for a new century. Journal of Counseling $\mathcal{E}$ Development, 84(2), 174-186.

Carroll, A. B., \& Shabana, K. M. (2010). The business case for corporate social responsibility: A review of concepts, research and practice. International Journal of Management Reviews, 12(1), 85-105.

Cheah, J.-H., Sarstedt, M., Ringle, C. M., Ramayah, T., \& Ting, H. (2018). Convergent validity assessment of formatively measured constructs in PLS-SEM: On using singleitem versus multi-item measures in redundancy analyses. International Journal of Contemporary Hospitality Management, 30(1), 3192-3210.

Chen, Y.-C., Hung, M., \& Wang, Y. (2018). The effect of mandatory csr disclosure on firm profitability and social externalities: Evidence from china. Journal of accounting and economics, 65(1), 169-190.

Cohen, J. (2013). Statistical power analysis for the behavioral sciences. Routledge.

Dhingra, D., \& Mittal, R. (2014). CSR practices in Indian banking sector. Global Journal of Finance and Management, 6(9), 853-862.

Ehsan, S., Nazir, M. S., Nurunnabi, M., Raza Khan, Q., Tahir, S., \& Ahmed, I. (2018). A multimethod approach to assess and measure corporate social responsibility disclosure and practices in a developing economy. Sustainability, 10(8), 2955. 
Erard, R. E., Meyer, G. J., \& Viglione, D. J. (2014). Setting the record straight: Comment on Gurley, Piechowski, Sheehan, and Gray (2014) on the admissibility of the Rorschach Performance Assessment System (R-PAS) in court. Psychological Injury and Law, 7(2), 165-177.

Fang, E., Palmatier, R. W., \& Steenkamp, J.-B. E. (2008). Effect of service transition strategies on firm value. Journal of Marketing, 72(5), 1-14.

Fornell, C., \& Larcker, D. F. (1981). Evaluating structural equation models with unobservable variables and measurement error. Journal of Marketing Research, 18(1), 39-50.

Frederick, W. C. (2016). Commentary: Corporate social responsibility: Deep roots, flourishing growth, promising future. Frontiers in Psychology, 7, 129.

Galbreath, J., \& Shum, P. (2012). Do customer satisfaction and reputation mediate the CSR-FP link? Evidence from Australia. Australian Journal of Management, 37(2), 211-229.

Gefen, D., \& Straub, D. (2005). A practical guide to factorial validity using PLS-Graph: tutorial and annotated example. Communications of the Association for Information systems, 16(1).

Girerd-Potin, I., Jimenez-Garcès, S., \& Louvet, P. (2014). Which dimensions of social responsibility concern financial investors? Journal of Business Ethics, 121(4), 559576.

Govindarajan, V., \& Amilan, S. (2013). An influence of CSR initiatives with financial performance: evidence from petro-gas products industry in India. Academicia: An International Multidisciplinary Research Journal, 3(8), 1-27.

Hair, J. F., Money, A. H., Samouel, P., \& Page, M. (2007). Research methods for business. Education+ Training, 49(4), 336-337.

Henseler, J., Dijkstra, T. K., Sarstedt, M., Ringle, C. M., Diamantopoulos, A., Straub, D. W., ... Calantone, R. J. (2014). Common beliefs and reality about PLS: Comments on rönkkö and evermann (2013). Organizational Research Methods, 17(2), 182-209.

Homburg, C., Stierl, M., \& Bornemann, T. (2013). Corporate social responsibility in business-to-business markets: How organizational customers account for supplier corporate social responsibility engagement. Journal of Marketing, 77(6), 54-72.

Hussain, A. B., \& Endut, N. (2018). Do decent working conditions contribute to work-life balance: A study of small enterprises in Bangladesh. Asia Pacific Journal of Innovation and Entrepreneurship, 12(1), 90-104.

Ikram, M., Sroufe, R., Mohsin, M., Solangi, Y. A., Shah, S. Z. A., \& Shahzad, F. (2019). Does csr influence firm performance? a longitudinal study of SME sectors of Pakistan. Journal of Global Responsibility, 11(1), 27-53.

Iqbal, N., Ahmad, N., \& Kanwal, M. (2013). Impact of corporate social responsibility on profitability of islamic and conventional financial institutions. Applied Mathematics in Engineering, Management and Technology, 1(2), 26-37.

Kafetzopoulos, D., Gotzamani, K., \& Skalkos, D. (2019). The relationship between efqm enablers and business performance: The mediating role of innovation. Journal of Manufacturing Technology Management, 30(4), 684-706.

Loh, L., Thomas, T., \& Wang, Y. (2017). Sustainability reporting and firm value: Evidence from Singapore-listed companies. Sustainability, 9(11), 2112. doi: 10.3390/ 
su9112112

McCarthy, D. J., Puffer, S. M., Dunlap, D. R., \& Jaeger, A. M. (2012). A stakeholder approach to the ethicality of bric-firm managers' use of favors. Journal of Business Ethics, 109(1), 27-38.

Mehar, A., Rahat, F., et al. (2007). Impact of corporate social responsibility on firm's financial performance. South Asian Journal of Management Sciences, 1(1), 16-24.

Parket, I. R., \& Eilbirt, H. (1975). The practice of business social responsibility: The underlying factors. Business Horizons, 18(4), 5-10.

Ramchander, S., Schwebach, R. G., \& Staking, K. (2012). The informational relevance of corporate social responsibility: Evidence from ds400 index reconstitutions. Strategic Management Journal, 33(3), 303-314.

Schafer, J. L. (1997). Analysis of incomplete multivariate data. CRC press.

Schwartz, M. S., \& Cragg, W. (2017). Corporate social responsibility. Routledge.

Soana, M.-G. (2011). The relationship between corporate social performance and corporate financial performance in the banking sector. Journal of Business Ethics, 104(1), 133-148.

Turker, D. (2009). Measuring corporate social responsibility: A scale development study. Journal of Business Ethics, 85(4), 411-427.

Venkatraman, N., \& Prescott, J. E. (1990). Environment-strategy coalignment: An empirical test of its performance implications. Strategic Management Journal, 11(1), 1-23. 